the whole case away in the plainest manner goes without saying.

But to the question: What is the explanation of the tremendous fact that, in spite of the giant strides which municipalities have been making in the direction of improved sanitary conditions ; in spite of the lavish spendingnot to say squandering-of public money on everything which holds out the least hope of sanitary betterment; in spite of the great army of sanitary officials which is exerting itself to the utmost to improve the public health, an authority is able to tell us to.day that scarlet fever is endemic in every large town in the United Kingdom. It will be granted that the contagious element of scarlet fever - the materies morbi-is al ways derived from a previous case. If, then, isolation be the remedy the aggregation of 93 per cent. (practically all) of notified cases must succeed in stamping out the disease at no distant date. If this end is not attained why is it not attained? Is it not a reasonable presumption that the explanation will be found in the continued infectivity of hospital discharged patients? But we are told that the number of persons who receive their infection through the medium of the hospital is so small that it may be regarded as a quantité négligeable. This notion is so preposterous that one cannot help a teeling of astonishment that medical scientists have allowed themselves to be blinded by a definition so stupid and mischievous as the accepted definition of a "return" case. Dr. Tonkin, who errs in good company, informs us that "the dangerous cases are from 2 to 5 per cent." A case, therefore, which slays at large is not a dangerous case because it does not conform with the postulate laid down that a "return" case must arise in the home. As a matter of fact, the definition, trammelled as it is by limits of place and time, does not give a scintillation of the extent of injury inflicted by these institutions. $\mathbf{A}$ discharged patient may sow the disease broadcast and for various and obvious reasons leave the home untouched. It frequently happens that the other inmates of the home have had a mild, though temporarily protective, attack immediately precedent to the removal of the only well-marked case to the hospital. There may be no other children in the home, or, if there are, these may have been protected (in so far as one attack does prevent the occurrence of another) by previous attacks, or may be naturally immune.

Dr. Tonkin thinks that the continued infectivity of the home (after removal) may account for some of the cases which pass for return cases. If this be the case he has advanced a second argument against removal; but new centres of infection are being constantly established by discharged patients who go elsewhere than to their own homes. Oases in point: 1. The relative of a distinguished professional man resident here went straight from the hospital to her home in a distant county, where she promptly spread the disease. 2. A little girl called on her way home from the hospital at the house of a relative, where she played for 20 minutes with her cousin. In a few days the cousin sickened and was presently dead from scarlet fever. 3. A well-known tradesman was asked by a Derby friend to receive the son of the latter into his home for a few weeks' change, the son being a recently discharged patient from the Derby Isolation Hospital. The only child of the host sickened a few days after the advent of the guest and died at the end of a fortnight. Not one of these cases, be it understood, fulfilled the conditions of a "return" case. They burden no annual reports and find no place in tabulated returns anywhere. They go, however, to swell the lists of notified cases and we find them again in the Registrar General's returns. Your correspondent says that these questions will have to be discussed and determined in the near future, and in that event graciously credits me with having accomplished some little good. I am obliged to him. When the investigation takes place it will be found that other questions which have not been raised by this discussion will assume great importance. Amongst these the high mortality rate of hospital-created cases and the occurrence and mortality rate of cases of secondary infection will bave to come under discus-sion. We shall also want to know a little more about that formidable disease, post-scarlatinal diphtheria, the incidence of which is dependent on life in hospitals and the mortality of which is 58.3 per cent. as against the 30.4 per cent. of cases of ordinary diphtheria. The discussion of questions of such serious import to us as a nation will have to be approached in a spirit somewhat different from that which some sanitarians contrive to infuse into discussions of the kind and it will have to be carried on unhampered by senseless formulæ and unlimited by meaningless definitions. I am, Sirs, yours faithfully,

Nottingham, Dec. 22nd, 1900. $\quad$ EdWARD Dean MARRIOTT.

\section{IS THERE A PSEUDO-DIPHTHERIA BACILLUS?}

To the Editors of THW LANOET.

SIRS,-The report of Dr. J. Priestley, summarised in THE LANCET of Dec. 22nd (p. 1821), deals with a ques tion of very great importance-namely, the possibility of distinguishing between the organisms of diphtheria and psendo-diphtheria for the purposes of clinical diagnosis. The question briefly amounts to this: Is it possible, in the time allowable for useful clinical diagnosis, to distinguish between these two with any degree of certainty justifying a negative report as to the existence of diphtheria? The question has been constantly before me during the last 12 months in which I have examined cultures from some 1800 throats made in connexion with the securing of the Greenwich Royal Hospital School against an outbreak of diphtheria. In only two or three of this number have I been able to identify anything as morphologically identical with Hoffmann's bacillus, and I certainly do not believe it to be wise or right to act upon such a presumption to the extent of treating such cases as non-infectious. Indeed, no one appears to take such a line, which is as much as to say that those who identify the organism in question, myself among the number, have not the courage of their convictions and dare not take the responsibility of acting upon their opinions. Moreover, it appears to be generally admitted that the one organism may be converted into the other. Surely this is to give up the whole position and to introduce a heresy which may attain very dangerous propor. tions. In order to preserve a distinction between two organisms, it must be shown that they are at all times and under all circumstances incapable of transmutation. If ever one can turn into the other, then the only logical deduction is that they are essentially identical.

Dr. R. T. Hewlett, who has studied this subject exhaustively, after giving a careful tabular statement of the differences between the two organisms, makes the damaging admission just referred to, the apparent possibility of conversion, and no conclusive one of the tests which he furnishes is capable of application within the time at the disposal of a clinical investigator. This being so, it seems plain that it is the duty of every person who bears responsibility in this respect to refrain, when an organism morphologically resembling the diphtheria bacillus is found in a culture, from stating that the organism so found is not a dangerous one.

The whole matter is, as I have said, summed up in the one statement which I desire to emphasise in every possible way-namely, that if there be a possibility of converting the pseudo-diphtheria bacillus into the diphtheria bacillus, then there is no such thing as a pseudo-diphtheria bacillus at all, and this is, I confess, my own present position.

I am, Sirs, yours faithfully,

EDWD. C. BOUSFIELD,

Dec. 22nd, 1900. Bacteriologist of the Borough of Camberwell.

\section{THE OPERATION OF CIRCOMCISION.}

\section{To the Editors of THE LANCET.}

SIRS -Mr. D'Arcy Power, in his interesting paper on Some Disappointments of Surgery, ${ }^{1}$ makes the following very apposite remarks:- "There are few operations more often performed than those of circumcision and for hare-lip, yet there are few which may give more disappointing results. The aim of a perfect circumcision is to remove just so much of the foreskin as is necessary to liberate the glans penis and to avoid removing so much as to leare the patient a 'curtus Judaus.' Such a perfect operation is rare, but I do not recollect that the difficulties were ever pointed out to me." It is undoubtedly true that such a perfect operation is rare, but why is this the case? The fact is that circumcision is generally regarded as a very simple operation and one which any surgeon feels competent to undertake, but if one may judge from a good many cases which come 
under notice from time to time the object of the operator would appear to have been not to remove just so much of the foreskin as is necessary to liberate the glans penis, but to cut away as much as possible of the prepuce without injuring the glans penis, which is thus left absolutely denuded from apex to base.

It may be presumptuous in me to suggest that possibly the text-books on surgery are partly to blame for the extensive mutilations which are frequently practised under the name of circumcision, but the usual method described in most books of placing the circumcision forceps over the line of the corona and then allowing the glans to slip out of the way when the whole of the skin beyond the forceps is cut off has always seemed to me to err in the direction of doing too much. The plan I have generally adopted and found successful is to first seize and gently draw out the end of the prepuce with a pair of artery forceps and then to apply the circumcision forceps not over the corona, but over the end of the glans penis which it just clears. With the subsequent retraction which immediately ensues and after the mucous membrane is slit up along the dorsum it will be found that quite sufficiént skin has been removed, no unnecessary mutilation has been produced, and the object of the operation has been satisfactorily attained.

All this may seem a small matter, but no detail, however small, is unworthy of attention in even the most trifling operations of surgery.-I am, Sirs, yours faithfully.

Gloucester, Dec. 24tb, 1900

DYKES BOWER, F.R.C.S. Edin.

\section{OACODYLATE OF SODIUM : A WARNING. To the Editors of THE LANCET.}

SIRS,-It is unfortunate that the lay press should have selected for recommendation as a popular remedy so lethal an agent as cacodylate of sodium. We are told that although it contains 55 per cent. of arsenious acid it has none of the toxic action of that drug and that it may be given by mouth in doses of from 20 to 40 centigrammes with perfect safety. This is not my experience. On Dec. 9 th $I$ ordered for a patient, aged 21 years, suffering from phthisis, one grain of cacodylate of sodium in a pill. On the following day there was a distinct odour of garlic in the breath and on the second day this was much more marked, was noticeable at some distance from the bed, and suggested the smell of phosphorus. On the third day the patient vomited twice and the odour of the breath was almost gangrenous in character. On the next day, after 11 doses had been taken, the patient was found to be suffering from many of the symptoms of arsenical poisoning. Her face was pallid, the eyelids were œdematous, the conjunctivæ were injected, the tongue presented the appearance of a piece of raw beef, and there was complete loss of appetite. In addi tion there was arsenical neuritis. The patient complained of pains in the limbs, especially in the lower extremities There was tenderness on deep pressure over the course of the nerves, more marked in the left leg than in the right. She was unable to move the left leg and there was marked loss of power in the extensors of the left wrist. The patellar reflexes were not abolished, but the attempt to elicit them caused great pain. There was no diarrhcea and there was no albumin in the urine. The odour of the breath disappeared within 24 hours of the suspension of the remedy and her general condition improved, bat the loss of power in the leg and in the arm still persists. The drug was obtained from one of the most reliable chemists in London and was made by Messrs. Pointet and Co. of Paris. It was given in about one-third the minimum dose recommended by Galliard and other French physicians and its effects were carefuily watched, but in spite of all precautions these untoward effects ensued. Gautier states that it may be given hypodermically, in doses of three-quarters of a grain. My experience may be exceptional, but I cannot but think that it is a dangerous remedy which should be employed with considerable caution. I am, Sirs, yours faithfully,

Welbeck-street, W., Dec. 16th, 1900.

WILLIAJ MURRELL

Royal College of StrRgeons in Ireland.The Carmichael prize of $£ 120$ has been awarded by the President, Vice-President, and council to Mr. Horatio Nelson Hardy.
NOTES FROM INDIA.

(From our Spheial Correspondent.)

Sanitary Improvements under the Epidemic Diseases Act.Municipal Subscriptions to the Pasteur Institute of India.-The Health of the Cities of Bombay and Calcutta.The Plague.

THE Epidemic Diseases Act has been made use of for other purposes than plague administration, and not the least of them has been the improvement and demolition of insanitary buildings. This Act gives powers not possessed by municipal authorities and bas been taken advantage of - in Bombay city, where during the past year 271 houses and sheds have been demolished and 629 declared unfit for human habitation. In addition compulsory improvements have been effected in a very large number. It is to be hoped that the powers thus given during a plague epidemic will be transferred to municipal authorities as a permanent measure. Few if any improvements have been carried out under these powers in Calcutta.

The authorities of the Pasteur Institute of India have been inviting certain municipal and district boards to contribute annual subscriptions in aid of the institute. At Lucknow, notwithstanding some opposition, it was carried that "as the Pasteur Institute is a scientific institution for the alleviation of the sufferings of humanity it should be aided by the board and that inquiries be made as to the financial condition of the institution with a view to the board's making a suitable grant." On the other hand, at Calcutta, where the application was rejected, it received opposition from the chairman of the municipal board and another European member.

The draft report of the municipal commissioner for the city of Bombay for 1899-1900 has lately been presented. In it he refers to the exceptional rainfall of only 35.9 inches, which was less than half the normal and half of which even occurred in the month of June, and he mentions how the water-supply became not only scanty but impure. At the same time the worst famine of the century commenced, causing local destitution in Bombay city and a large immigration of destitutes from the famine-stricken areas. The mortality of the city has been very high, there having been 4473 more deaths than in 1898 and the death-rate has been 68.67 per 1000 per annum. The total deaths for the year were 56,434 , being 17,785 above the average. In the month of March when plague was at its worst 10,183 death were recorded. Plague is credited with 15,796 victims, and diseases of the respiratory system caused 8650 deaths, phthisis 6029 deaths, fevers 5063 deaths, and diarrhoea and dysentery 4286 deaths.

In consequence of the high infantile and maternal mortality in Bombay city the municipality has appointed a committee "to consider and report on the desirability of entertaining one or more diplomaed native midwives for each ward of the city for giving relief to poor women in need of assistance at childbirth." At present the women doing this work are ignorant and dirty and they spread disease far and wide.

The general mortality in Bombay city shows no signs of diminution. For the week ending Dec. 4th it was 804 as against 790 during the previous seven days. During the past quarter it has been at the rate of 84.09 per 1000 per annum. Amongst high-caste Hindus the rate is 79.72 per 1000 , amongst Mahomedans 83.55 , amongst Parsees 38.51 , and amongst Europeans $39 \cdot 32$.

The general mortality in Calcutta is also high and shows no sign of diminution. For the week ending Dec. 1st there were 681 deaths, against an average of 552 , a rate of $52 \cdot 1$ per 1000 , against an average of 42.2 . In both cities plague seems again on the increase. 70 deaths are recorded this week in Bombay and 76 in Calcutta.

Plague has again broken out in the Punjab and at Bangalore it has much increased. The members of the dhobie (washerman) class are the chief sufferers there.

Dec. Sth, 1900. 